\title{
Channeling Janus: Past, Present, and Future in the RBMS Membership Survey
}

\section{Introduction}

In 2015, the Rare Books and Manuscripts Section (RBMS) surveyed its membership for the first time in 18 years. ${ }^{1}$ At roughly the span of a generation, 18 years is a long time in the rapidly changing world of libraries. Consider, for example, that in 1997 J.K. Rowling had just released the first Harry Potter novel, Google was a year away from being founded, and fewer than half of the respondents to the first RBMS Membership Survey had access to e-mail and the Internet at home. New landscapes call for new data, and the 2015 RBMS Membership Survey answers that call. Its findings contribute to our understanding of the past, present, and future of special collections professionals.

The 60 questions of the 2015 survey address members' demographics, RBMS involvement, positions, institutional settings, and perspectives on the future of the profession. Sponsored by the RBMS Membership and Professional Development Committee, the survey sets out to track changes in the field since the last member survey in 1997 and to provide data that can inform decision making and change within the RBMS organization and the special collections profession.

RBMS was established as a section within the Association of College and Research Libraries (ACRL), a division of the American Library Association (ALA), in 1958. It "strives to represent and promote the interests of librarians who work with rare books, manuscripts, and other types of special collections."2 RBMS develops guidelines and standards, provides professional development and continuing education opportunities (most notably at its annual conference), promotes research in the field, and facilitates communication in the special collections community.

1. The authors would like to thank those who generously participated in the review of the 2015 RBMS Membership Survey questions and tool, including the Membership and Professional Development Committee (M\&PD) survey team (Kathryn Brooks, Kevin Butterfield, Alison Clemens, Cait Coker, Anna Dysert, Cheryl Morrison, Charlotte Priddle, and Kimberly Tully); M\&PD Committee Chairs past and present (Meghan Constantinou, Katie Henningsen, and Melanie Meyers); various RBMS Committee Chairs and members and RBMS Executive Committee members, especially 2014-2015 RBMS Chair R. Arvid Nelsen; Kathy Rosa and Norman Rose of the ALA Office of Research and Statistics; and ACRL staff members David Free, Megan Griffin, and Tory Ondrla, who assisted in the dissemination of the survey.

2. Rare Books and Manuscripts Section (RBMS) Website, American Library Association, available online at http://rbms.info/ [accessed 14 September 2015]. 
Although the survey results offer particular insight into RBMS as an organization, the respondents also represent a cross-section of the special collections field more broadly, as they come from a wide variety of institutions and positions. Some are deeply involved in RBMS (23 percent have held at least three committee or task force appointments), ${ }^{3}$ whereas others are less active (41 percent of respondents have never attended an RBMS Conference). ${ }^{4}$ The results, then, provide a unique opportunity to hear from the many voices within the profession, including those not able to contribute at conferences and committee meetings.

As special collections professionals are increasingly called to demonstrate the value of their collections and services, it becomes all the more important to know who we are as a community, how we have changed, and how we might continue to transform to meet the needs of our field. This article, like the modern special collections professional, wears many hats: it is part summary of findings, part comparative analysis, and part identification of areas for action and future study. Overall, it presents and discusses key findings of the survey, including the shifting demographics of the section, noteworthy correlations with respect to gender, diversity, salary, and administrative positions, and areas of heightened concern, such as how expense impacts members' ability to participate.

\section{Survey History and Related Studies}

Membership surveys for professional organizations often entail a combination of member and employment demographics, information on members' interactions with, perceptions of, and aspirations for the organization, and larger questions that address the state of a given field. Although the American Library Association has a long history of membership surveys, both as a parent organization and among its subsidiary divisions and sections, the most immediate predecessor of the 2015

3. Q23. Throughout this article, the 2015 RBMS Membership Survey questions from which the findings derive will be referenced in the footnotes: for example, Q23. The full survey questionnaire is available on the Membership and Professional Development Committee page on the RBMS website: "2015 RBMS Membership Survey Questionnaire" (questionnaire, Rare Books and Manuscripts Section, Association of College and Research Libraries, American Library Association, 2015), available online at http://rbms.info / files/committees/membership_and_professional/2015_RBMS_Membership_Survey_Questionnaire.pdf [accessed 6 March 2016]. Readers may also wish to consult the 2015 survey data report, which includes the full response set to the free text questions: "2015 RBMS Membership Survey: Data Report" (report, Rare Books and Manuscripts Section, 2015), available online at http://rbms.info/files/committees/membership_and_professional/2015_RBMSDataReport.pdf [accessed 25 February 2016]. On occasion, we will also reference the 1997 RBMS Membership Survey questions, for example, Q23 (1997). The 1997 survey questions and results are available in Brad Oftelie, "Results of the 1997 Membership Survey of the Rare Books and Manuscripts Section (RBMS), Association of College and Research Libraries, American Library Association Analyzed and Reported by Brad Oftelie, Member RBMS Membership Committee" (report, Membership and Professional Development Committee, Rare Books and Manuscripts Section, Association of College and Research Libraries, American Library Association, 1997), available online at http:/ /rbms. info/files/committees/membership_and_professional/rbms-survey97.pdf [accessed 3 June 2015].

4. Q15. 
RBMS Membership Survey was the section's first membership survey, conducted in 1997. The 1997 survey was executed by what was then called the RBMS Membership Committee, chaired by Suzy Taraba, with the aim of "surveying members for demographic information, as well as information about members' positions and their involvement in RBMS and other organizations." "The resulting report, authored by committee member Brad Oftelie, showed an organization concerned with issues that will seem familiar: "funding, technology, preservation, support from parent institutions, justifying existence/relevance, outreach, continuing education/training.”6 In his report, Oftelie recommends administering the survey every five years, perhaps focusing on a particular subset of the data in order to whittle away at the survey's daunting length. ${ }^{7}$ The 2015 RBMS Membership Survey is the first such survey to be administered since 1997.

Membership surveys conducted by ACRL (the parent division of RBMS), by the Society of American Archivists (SAA), and within the broader archival profession offer further sources of comparative data. These surveys provide benchmarks from overlapping disciplines and will be invoked throughout this article, particularly with respect to demographic data. ACRL surveys its members at three-year intervals, most recently in spring 2015. Although not widely released, the findings of the 2012 ACRL Membership Survey, the most recent available at the time of writing this article, were shared in at least two documents: a final report made available to ACRL leadership, which offered an overview of the survey data, and a crosstabulated report distributed to section membership chairs in spreadsheet form, which presented the numeric data in total and subdivided by the ACRL sections that respondents identified as their primary affiliation. ${ }^{8}$

The Society of American Archivists (SAA) is a national organization for the archival profession with which RBMS shares many members. It has a long, if irregular, history of surveying its membership extending back to the SAA Membership survey of $1956 .^{9}$ Its 2012 member survey, administered by the firm

5. Oftelie, “1997 Membership Survey,” 1.

6. Ibid., 33.

7. Ibid., 1 .

8. Mary Jane Petrowski and Avenue M Group, LLC, "2012 ACRL Membership Survey: Final Report" (report, Association of College and Research Libraries, 2012), available online at http:/ / connect.ala.org/files / Doc\%201.0\%20ACRL\%202012\%20Membership\%20Report\%202012\%20FINAL\%2011-19-12\%5B2\%5D.pdf [accessed 2 August 2015]; "ACRL 2012 Membership Survey: Cross Tab Report: ACRL Section Interest Group Cross Tab" (report, Association of College and Research Libraries, 2012), available online at http:/ / connect. ala.org/files/45259/ ACRL-Crosstab-Report--11-14-12-.xlsx [accessed 14 July 2015].

9. Ernst Posner summarizes the 1956 SAA Member survey report in Ernst Posner, "What, Then, Is the American Archivist, This New Man?" American Archivist 20, no. 1 (Jan. 1957): 3-11, available online at http:/ / americanarchivist.org/doi/pdf/10.17723/aarc.20.1.10h7186h04u21887 [accessed 13 November 2015]. For a listing of surveys of the archival profession, see "Appendix A: Survey Research, Statistical Analyses, and Environmental Scans within Archival and Allied Professional Communities,1956-2003," in Victoria Irons Walch et al., "A`CENSUS (Archival Census and Education Needs Survey in the United States)" (enhanced final report, Society of American Archivists, 2006), 529-30, available online at http:// www2.archivists.org/sites/all/files/ACENSUS-Final.pdf [accessed 5 August 2015]. 
Association Metrics, was primarily a member loyalty study whose goal was "to better understand which benefits and programs members value, and how well they believe SAA is doing in delivering those experiences." ${ }^{10}$ Of note for the wider cultural heritage field is a survey that SAA led in 2004. Its purview extended beyond the SAA membership to target the archival profession more broadly. Distributed to just under 12,000 people, including members of 59 archival associations, "A*CENSUS (Archival Census and Education Needs Survey in the United States)" yielded 5,620 responses to produce what its principal research consultant Victoria Irons Walch hailed as "a comprehensive picture of the archival profession and its people early in the twenty-first century." ${ }^{11} \mathrm{~A}$ somewhat abbreviated version of the survey findings was published in a set of eight topic-oriented reports in American Archivist in 2006, and the ambitious scope of the project is suggested by the length of the 328-page full survey report made available on the SAA website. ${ }^{12}$ Despite the differing foci of these surveys, their findings enable points of comparison between RBMS and its closest peer organizations and professions.

\section{Methodology}

The Membership and Professional Development Committee of RBMS began plans for a new membership survey in 2014, although initial discussions and research had started several years prior. A survey team was formed, led by the authors. The 2015 survey was modeled closely on the 1997 survey, with the goal of gathering longitudinal data in three main areas: RBMS membership demographics ("Section I: You"), member participation in and opinions regarding RBMS activities and the field of special collections ("Section II: RBMS Involvement"), and employment history and institutional settings ("Section III: Your Current Position" and "Section IV: Your Previous Position"). ${ }^{13}$ Some questions were reworded or replaced to reflect changes in the special collections environment or to address methodological problems noted by the administrators of the

10. "Society of American Archivists Member Needs \& Satisfaction Survey" (report, Association Metrics, Society of American Archivists, 2012), 5, available online at http:/ / files.archivists.org/membership/surveys/saaMemberSurvey-2012r2.pdf [accessed 14 July 2015].

11. Victoria Irons Walch et al., "A*CENSUS (Archival Census and Education Needs Survey in the United States)," American Archivist 69, no. 2 (Fall/Winter 2006), available online at http: / /americanarchivist.org/doi/pdf/10.17723/aarc.69.2.d474374017506522 [accessed 5 August 2015]. The condensed version of the $\mathrm{A}^{\star} \mathrm{CENSUS}$ report was published in American Archivist (237 pages), and the full survey report, which also bears the American Archivist headers, was posted on the SAA website ( 328 pages). For clarity's sake, abbreviated citations will use "(enhanced final report)" when referring to the expanded version published on the SAA website.

12. Walch et al., "A`CENSUS" (enhanced final report), 294.

13. In this article, analysis of the survey data generally conforms to the survey sections as outlined above. For ease of discussion, however, geography (Q36, Q37, Q48, Q49) is discussed with the demographic data of Section I, and educational background (Q4) is discussed alongside position and institutional settings data of Sections III and IV and the current salary data of Section V. 
1997 survey. ${ }^{14}$ Several new questions were included to address areas in need of additional data. ${ }^{15}$

During the preparation of the questionnaire, the survey team sought feedback from several RBMS committees, the RBMS Executive Committee, ACRL, and the ALA Office of Research and Statistics. Once all changes were made to the survey text, it was reviewed and approved by the Membership and Professional Development Committee and the Executive Committee.

The survey was administered using the Qualtrics survey tool. On April 6, 2015, RBMS members were invited to participate via a direct e-mail solicitation containing a link to the questionnaire. Two reminder e-mails followed, and the survey officially closed on May 11, 2015. ${ }^{16}$ The survey invitation was distributed to the 1,456 RBMS members whose ALA communication settings permitted contact, and 403 members completed the survey, yielding a response rate of 28 percent. ${ }^{17}$ This more than doubled the response rate of 12 percent for the 1997 survey, which was conducted on paper via post (221 responses for 1,800 surveys mailed out)..$^{18}$

To draw out particular trends and data points, the authors have subjected the raw data to further analysis, including the coding of free text answers, cross tabulations, and filtering by subject group(s). Unless otherwise specified, percentages reported in this article are tabulated using the total number of responses received for a given

14. For example, a question from the 1997 survey that asked about Internet and e-mail access at home and at work, Q11 (1997), was replaced with a question targeting members' use of online publishing platforms and social media applications, Q11 (2015). In questions 38a (current position) and 50 (previous position), several new options were added to the position types: curator (mixed or other formats), digital collections librarian/archivist, metadata librarian, special collections outreach and/or instruction librarian, and student library position. The question treating race and ethnic identification, Q3, was updated to reflect recent guidelines on wording offered by the Equal Employment Opportunity Commission.

15. New questions added to the 2015 Survey include ones addressing RBMS Conference scholarships (Q32), faculty status (Q38b, Q38c), social media (Q11), preferences regarding the geographic and temporal proximity of ALA Annual and the RBMS Conference (Q22c), and factors influencing members' decisions whether or not to attend both conferences in a given year (Q22d).

16. Because a number of members reported not receiving the invitations sent out by ALA using the Informz e-mail marketing service, the final e-mail solicitation was sent out directly by Elspeth Healey. The survey was also promoted more broadly through RBMS social media accounts and on the RBMS Chair's Blog; however, these sources referred RBMS members to the invitation e-mail for access to the survey link.

17. During the month of April 2015, the total number of individual RBMS members was 1,651; thus, the 403 responses constitute participation by 24 percent of the total number of RBMS individual members. However, the response rate was calculated using the number of members to whom the survey was distributed, which included only those individual members whose communication settings permitted contact and for whom ALA had an e-mail address on record. In addition to the 403 complete responses, 85 partial responses were received, but these were not included in the survey data and were not used when calculating the response rate.

18. Oftelie, “1997 Membership Survey,” 1. 
question, which may sometimes be fewer than $403 .{ }^{19}$ For ease of reading, percentages are rounded to whole numbers, at times resulting in totals that either fall short of or exceed 100 percent.

\section{Results and Discussion Our Members \\ DEMOGRAPHICS}

Overall, respondents to the 2015 RBMS Membership Survey were younger, more predominantly female, and slightly more diverse than in 1997. Modern librarianship has become a largely female profession, and RBMS is no exception; however, the 2015 survey suggests that the feminization of the field is becoming even more pronounced. In 1997, women comprised 64 percent of respondents, and in 2015 that number rose to 74 percent. ${ }^{20}$ The increase in women (and drop in men, from $36 \%$ to $23 \%$ ) is a trend that spans other library and archives organizations. In 2004, women comprised 65 percent of respondents to " ${ }^{\star}$ CENSUS (Archival Census \& Education Needs Survey in the United States)." ${ }^{21}$ Less than a decade later, 74 percent of respondents to SAA's 2012 Member Needs \& Satisfaction Survey were female. ${ }^{22}$ Women account for an even higher percentage of respondents to ACRL's 2012 Membership Survey. There, 79 percent of respondents were female, up from 68 percent in $1997 .{ }^{23}$

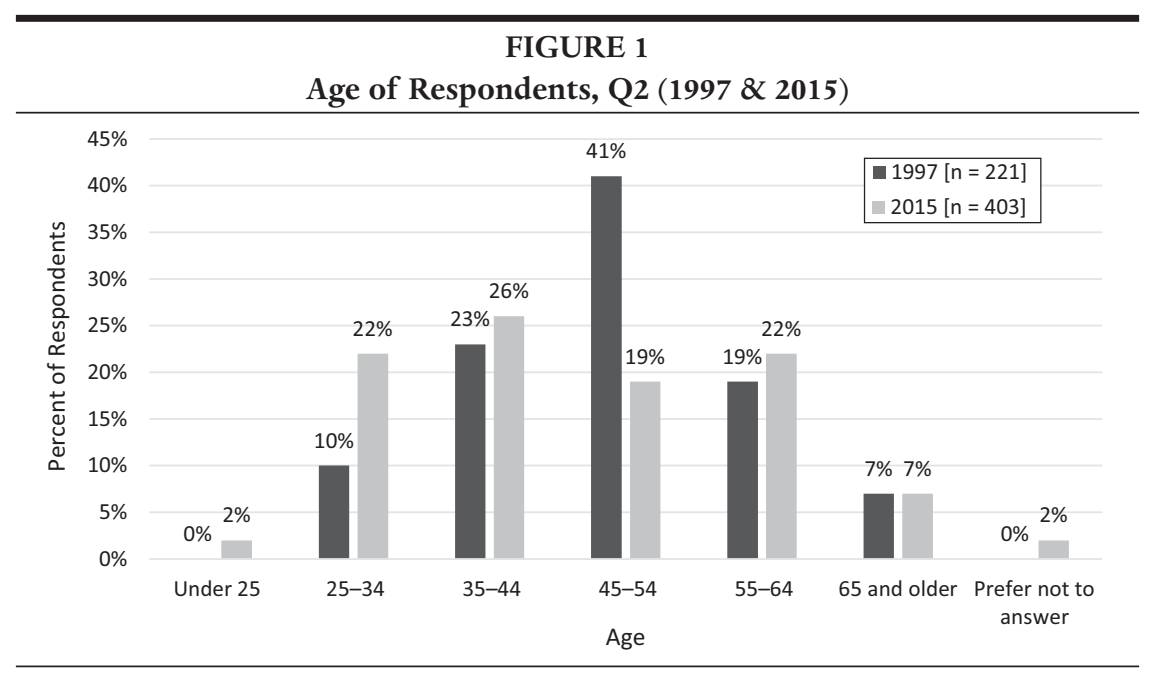

19. For example, only respondents who answered "Yes" to Q27a "Have you ever dropped your RBMS membership?" were prompted to answer Q27b "Why did you drop your membership? [check all that apply]." Thus only 59 responses were received for Q27b.

20. Q1.

21. Walch et al., "A`CENSUS," 329 .

22. This percentage is the SAA survey's "Valid Percent" (which excludes "Rather not say" and missing system responses). When "Rather not say" and missing system responses are included, the percentage falls to 72 percent. "Society of American Archivists Member Needs \& Satisfaction Survey: Frequency Distribution Report" (report, Society of American Archivists, 2012), 59, available online at http:/ / files. archivists.org/membership/surveys/saaSurvey-2012-FreqDistributions.pdf [accessed 3 August 2015].

23. Petrowski, "2012 ACRL Membership Survey: Final Report," 7 (Table 1.1). 
Age is another area that saw significant movement between the 1997 and 2015 surveys. In 2015 , members were relatively evenly distributed among the age brackets, with the 35-44 age cohort being the best represented at 26 percent. By contrast, in 1997,41 percent of respondents fell into the $45-54$ age bracket, making it that survey's dominant age cohort. ${ }^{24}$

Comparatively then, the 2015 membership skews younger, with a striking drop in the 45-54 age bracket from first to fourth place. A similar drop in the archival profession suggests that the dip isn't simply a statistical anomaly. The 45-54 age cohort constituted the largest group in the $2004 \mathrm{~A}^{\star} \mathrm{CENSUS}$ survey at 32 percent, but it comprised only the third-largest age cohort (at 18\%) in SAA’s 2012 Member Needs \& Satisfaction survey, behind the younger 25-34 (32\%) and 35-44 (22\%) cohorts. ${ }^{25}$ In ACRL Membership Surveys, the 45-54 age cohort dropped from 42 percent of respondents in 1997 to 23 percent in 2012. ${ }^{26}$ Indeed, the ACRL statistics show that, after reaching 43 percent in 2000, this age group has fallen in each successive survey. ${ }^{27}$ These findings, which may be linked to national population trends associated with the baby boom, suggest that, while there is a heartening influx of younger members into the field, the reduced size of the 45-54 age cohort could contribute to a temporary leadership gap and diminished opportunity for younger professionals to learn from those who have gone before.

In 1997, few respondents reported being a member of underrepresented groups. Ninety-five percent of those surveyed identified as white, with the 1997 categories "Black (except Hispanic)," "Hispanic," and "Other" accounting for only 1 percent each of respondents. ${ }^{28}$ In all, only nine of the 221 respondents (or 4\%) in 1997 reported belonging to a racial or ethnic minority (including "other"), with an additional two respondents abstaining.

In the years since the 1997 Membership Survey, RBMS has increasingly recognized the need for improved diversity both within the section and the special collections field. One step toward addressing this was through the formation of a Task Force on Diversity (2002-2004), which led in turn to the Diversity Action Plan Task Force (2004-2005) and the creation of the RBMS Diversity Action Plan. In the wake of

24. Q2 (1997 \& 2015).

25. Walch et al., "A`CENSUS” (enhanced final report), 354 (percentage calculated using Table 3.3.8, combining the 45-49 and 50-54 age cohorts across employer type); "Society of American Archivists Member Needs \& Satisfaction Survey” (summary report), 10.

26. Petrowski, "2012 ACRL Membership Survey: Final Report," 7 (Table 1.2).

27. The 45-54 age cohort accounted for 39 percent of ACRL members in 2003, 34 percent in 2006,27 percent in 2009, and 23 percent in 2012. Petrowski, “2012 ACRL Membership Survey: Final Report," 7 (Table 1.2).

28. Q3 (1997). There were no respondents in the 1997 survey who identified as belonging to the survey category “American Indian or Alaska Native.” Oftelie, “1997 Membership Survey," 5. 
this important work, the RBMS Diversity Committee was established as a standing committee in $2005 .{ }^{29}$

The 2015 survey suggests that the diversity of RBMS has increased somewhat; in 2015, African American members rose to 3 percent of respondents, and Latino or Hispanic members increased to 5 percent. ${ }^{30}$ In all, 11 percent of respondents identified as belonging to an underrepresented group. Yet, in spite of these gains, the racial and ethnic composition of RBMS remains less diverse than that of the U.S. population. Respondents remain largely white at 87 percent, eight percentage points above that group's representation among college-educated Americans 25 years and older $(79 \%){ }^{31}$

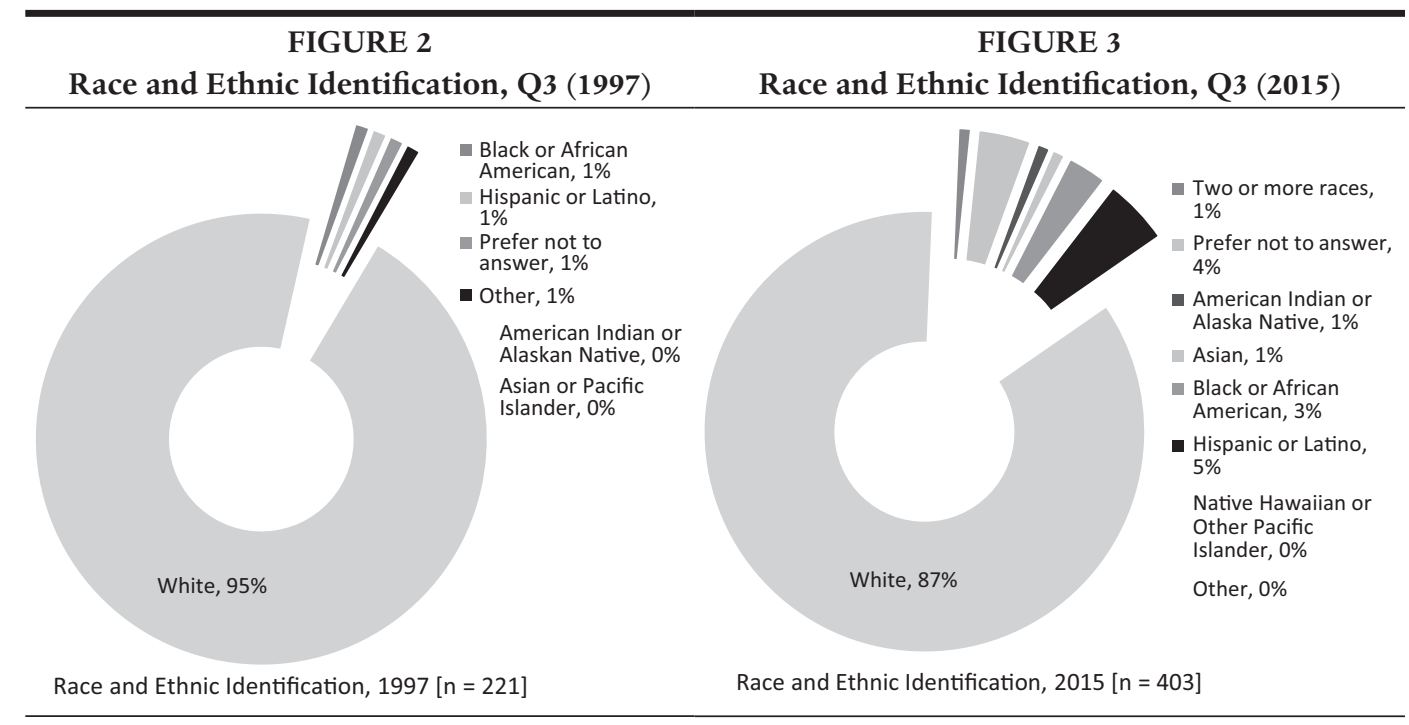

With respect to racial and ethnic diversity, RBMS is comparable to the archival profession and slightly less diverse than the larger field of academic librarianship. In the 2012 SAA Membership Survey, 11 percent identified as belonging to racial and ethnic minorities (including "other"), 87 percent identified as white, and 5 percent

29. "About: Commitment to Diversity," RBMS, available online at http://rbms.info/about/\#diversity [accessed 13 September 2015].

30. Q3.

31. Percentage calculated for the category "White alone" in relation to the total U.S. Population 25 years and older with an educational attainment of a bachelor's degree or higher. Since this percentage records only race, it includes individuals who may identify as Hispanic or Latino, making it an imperfect comparison with the 2015 survey data. U.S. Census Bureau, "S0201, Selected Population Profile in the United States, 2014 American Community Survey 1-Year Estimates," available online at http: / factfinder.census.gov/bkmk/table/1.0/en/ACS/14_1YR/S0201/ [accessed 9 November 2015]. The representation of the category "White alone, not Hispanic or Latino," in the general U.S. population is 62 percent. U.S. Census Bureau, QuickFacts Beta: United States, July 1, 2014 (V2014), available online at www.census. gov/quickfacts/table/PST045214/00 [accessed 1 November 2015]. 
preferred not to say; in ACRL's 2012 Membership Survey, 13 percent of respondents identified as belonging to racial or ethnic minorities (including "other"), 81 percent identified as white (down from $91 \%$ in 1997), and 6 percent preferred not to say. ${ }^{32}$ Attracting and retaining a diverse membership was a strong thread in several of the 2015 RBMS survey's free text responses, with one member remarking, "Lack of diversity in the field lessens our impact across the board-unless we can connect to the people who donate our diverse materials, we risk losing their trust. [... $]^{33}$

With respect to geography, the five states with the highest representation in the 2015 RBMS survey were California, New York, Pennsylvania, Texas, and Connecticut, with these states accounting for 38 percent of the survey population. ${ }^{34}$ These top states remain largely the same as in 1997, with the exception of Texas replacing Illinois in this group. In 2015, 2 percent of respondents were from Canada, 0.5 percent were from other countries, and 6 percent elected not to provide their location. ${ }^{35}$ The dominance of California ( $13 \%$, or 51 respondents) and New York ( $9 \%$, or 36 respondents) in the 2015 RBMS survey is even more pronounced than within the 2012 Membership Survey of RBMS's parent organization ACRL, wherein California accounted for 8 percent, followed by Pennsylvania, New York, and Illinois at 6 percent each of respondents. ${ }^{36}$

Despite a sizable early-career cohort ( 25 percent of respondents have been professionals in the special collections field for four years or fewer), much experience resides within the RBMS membership. ${ }^{37}$ More than one-third (34\%) of respondents have been professional librarians or archivists for 20 years or more ${ }^{38}$ however, only 20 percent have been in the special collections field for that length of time. ${ }^{39}$ While 45 percent of respondents have spent time as paraprofessionals in the field, only 2 percent selected "library/archive paraprofessional" as the description that most closely matches their current position. This may suggest that work as a paraprofessional is a common stage along the career trajectories of many RBMS members. ${ }^{40}$

32. The 2015 RBMS Membership Survey and 2012 SAA survey permitted respondents to elect more than one answer option for the race and ethnic identification question, thus the question totals are out of 102 percent (RBMS) and 103 percent (SAA), respectively. By contrast, the ACRL 2012 Membership Survey total for the question addressing race was 100 percent. "Society of American Archivists Member Needs \& Satisfaction Survey: Frequency Distribution Report,” 59-60; "ACRL 2012 Membership Survey: Cross Tab Report,” Q31; Petrowski, "2012 ACRL Membership Survey: Final Report," 7 (Table 1.0).

33. Response 34, Q33.

34. Q36. Percentage calculated using base survey population of 403, including those who elected to skip the question.

35. Q36, Q37. Percentage calculated using base survey population of 403.

36. Petrowski, "2012 ACRL Membership Survey: Final Report," 5.

37. Q6.

38. Q5.

39. Q6.

40. Q6a, Q38a. It is also possible that some of this divergence may result from respondents in paraprofessional positions identifying more closely with position titles that describe the nature of their work (such as public services librarian or technical services librarian) as opposed to their employment category (paraprofessional), leading them to select those as their current positions. 
More than one in five respondents (21\%) have worked as teaching faculty, and 11 percent have worked in the book trade. ${ }^{41}$

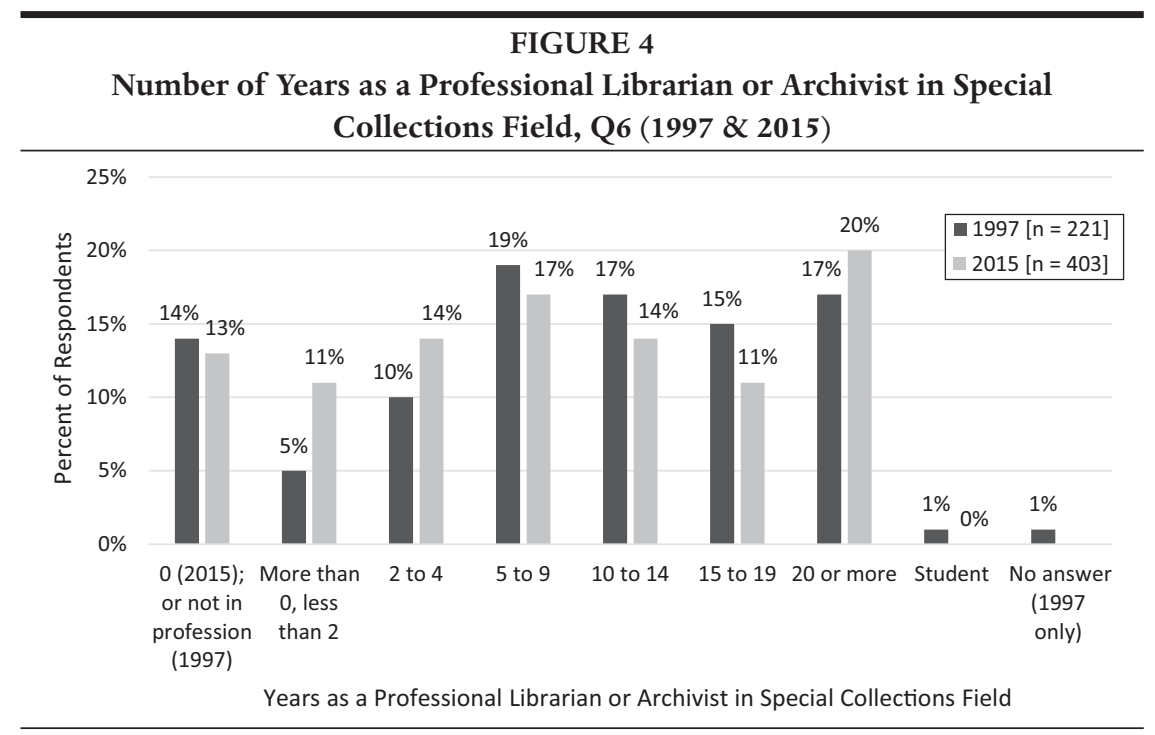

\section{PARTICIPATION IN PROFESSIONAL ORGANIZATIONS}

Most respondents (55\%) do not participate in ALA Divisions and Round Tables beyond ACRL. For those who do, the two most popular divisions are the Association for Library Collections \& Technical Services (ALCTS) (21\%) and Reference \& User Services Association (RUSA) $(10 \%) .{ }^{42}$ Within ACRL, members most frequently belong to the following sections in addition to RBMS: University Libraries Section (ULS) (21\%), College Libraries Section (CLS) (13\%), and Western European Studies Section (WESS) (12\%); however, an even larger segment of respondents (33\%) reports no section membership beyond RBMS. ${ }^{43}$ Among other professional organizations, the Society of American Archivists (SAA) shares the most members with RBMS: 30 percent of all respondents belong to SAA, up from 19 percent in $1997 .{ }^{44}$ This growth in SAA membership is paired with a drop in membership in organizations associated with print materials. Among respondents, American Printing History Association (APHA) membership fell from 24 percent in 1997 to 9 percent in 2015, and Bibliographic Society of America (BSA) membership fell from 19 percent to 7 percent. Though further study is needed, this may signal a shift in emphasis among formats within our collections, a

41. Q7. Percentage calculated using base survey population of 403.

42. Q8.

43. Q9.

44. Q10 (1997 \& 2015). 2015 percentage calculated using the number of SAA members (119) divided by the total survey population (403). 
trend that some booksellers report anecdotally from the collection development front. ${ }^{45}$

\section{SOCIAL MEDIA AND LISTSERVS}

Members cite Facebook, blogs, and Twitter as their three most-used online publishing or social media platforms (see table 1). Respondents consume social media content at a higher rate than they generate it, and when they do create content, they are more likely to do so on personal as opposed to institutional accounts. Nevertheless, 22 percent of members report creating institutional content for Facebook on a weekly basis, and 19 percent each for Twitter and blogs. Blogs are the only arena in which a greater number of members produce institutional content (19\%) as opposed to personal content $(11 \%){ }^{46}$

\begin{tabular}{|c|c|c|c|}
\hline \multicolumn{4}{|c|}{$\begin{array}{c}\text { TABLE } 1 \\
\text { Online Publishing Platforms and Social Media Applications by Type of } \\
\text { Weekly Use, Q11 }\end{array}$} \\
\hline & Read & $\begin{array}{c}\text { Create content } \\
\text { (personal account) }\end{array}$ & $\begin{array}{c}\text { Create content } \\
\text { (institutional account) }\end{array}$ \\
\hline Blogs & $67 \%$ & $11 \%$ & $19 \%$ \\
\hline Facebook & $64 \%$ & $51 \%$ & $22 \%$ \\
\hline Instagram & $20 \%$ & $17 \%$ & $5 \%$ \\
\hline Pinterest & $20 \%$ & $14 \%$ & $3 \%$ \\
\hline Twitter & $37 \%$ & $28 \%$ & $19 \%$ \\
\hline Tumblr & $20 \%$ & $9 \%$ & $9 \%$ \\
\hline Other (please specify) & $2 \%$ & $1 \%$ & $2 \%$ \\
\hline \multicolumn{4}{|c|}{$\begin{array}{l}\text { Note: For the purposes of the survey, respondents were asked to report which applications } \\
\text { they use on a regular (weekly) basis. Percentages reported are calculated using the total } \\
\text { number of survey respondents }(n=403) \text {. }\end{array}$} \\
\hline
\end{tabular}

In an age where e-mail inboxes often threaten to topple into chaos, listservs nevertheless play an important role in the field. Eighty-nine percent of respondents read at least one listserv on a regular basis: 68 percent read the RBMS listserv (up from 46\% in 1997), 48 percent read the ExLibris listserv (down from 57\%), and 34 percent read Archives \& Archivists (SAA) (up from 12\%). Other frequently cited listservs include those of the Society for the History of Authorship, Reading,

45. See, for example, bookseller Nina Musinsky's assertion, "The bottom line is that the item or group of items that appears to be unique, be it manuscript, archival, or ephemeral is currently desirable," "Marketplace" Plenary (2014 RBMS Preconference, Las Vegas, NV, June 26, 2014), available online at http: / /rbms.info/conferences2/preconfdocs/2014/talks/2014_plenary2.mp3 [accessed 23 February 2016], 0:26:23.

46. Q11. 
and Publishing (SHARP) (12\%) and Descriptive Cataloging of Rare Materials (DCRM) $(6 \%)^{47}$

\section{Our Profession and Involvement in RBMS MEMBERSHIP IN RBMS}

As noted above, the 2015 survey records a significant number of earlier-career professionals among RBMS members: 68 percent of respondents have been members of RBMS for nine years or fewer (as compared with $57 \%$ in 1997). The largest cohort consists of members who have been in the organization for two years or fewer (at 26\%), while those who have been members for 15-19 years are the smallest cohort (at $7 \%)^{48}$

Personal contact is central to how new members discover RBMS. The majority of respondents first learned of the organization through either a colleague (53\%) or a library school faculty member $(23 \%) .{ }^{49}$ However, after joining, members rely primarily on mass communications to stay current on the organization. Members cite the RBMS and ExLibris Listservs (67\%) and the RBMS website (64\%) as the most consulted sources for obtaining information on RBMS..$^{50}$ The three most commonly cited motivations for joining RBMS are the "opportunity for professional development" (347 responses), "opportunity to meet colleagues" (263 responses), and "opportunity to contribute to the profession" (218 responses)..$^{51}$

Only 15 percent of respondents report having dropped their membership at some point, with expense cited as the most common reason for that lapse $(51 \%) ;{ }^{52}$ however, since the survey captures only those who are current members, information on causes and rates of attrition might be more accurately captured by the Membership and Professional Development Committee's forthcoming "Dropped Member Survey."

\section{CONFERENCE ATTENDANCE AND COMMITTEE PARTICIPATION}

Continuing education and the RBMS Conference stand as the top two reasons that 2015 survey respondents maintain their RBMS membership. ${ }^{53}$ While such findings suggest that conferences lie at the heart of what RBMS members value, other data points

47. Q12 (1997 \& 2015). These percentages were calculated using the number of respondents who reported reading individual listservs divided by the total survey populations ( 221 and 403 , respectively). The percentages reported for the SHARP and DCRM listservs were generated by counting the number of times those listservs were cited in the "other" category.

48. Q13 (1997 \& 2015).

49. Q14a.

50. Q29.

51. Q14b.

52. Q27a, Q27b

53. Q30. 
remind us that there are many who, although invested in the organization (they were, after all, willing to complete a lengthy questionnaire!), do not attend RBMS and ALA conferences. The numbers begin to offer a picture of this divide. Forty-one percent of 2015 respondents have never attended an RBMS conference (up from 32\% in 1997); however, 20 percent have attended at least six RBMS conferences. ${ }^{54}$

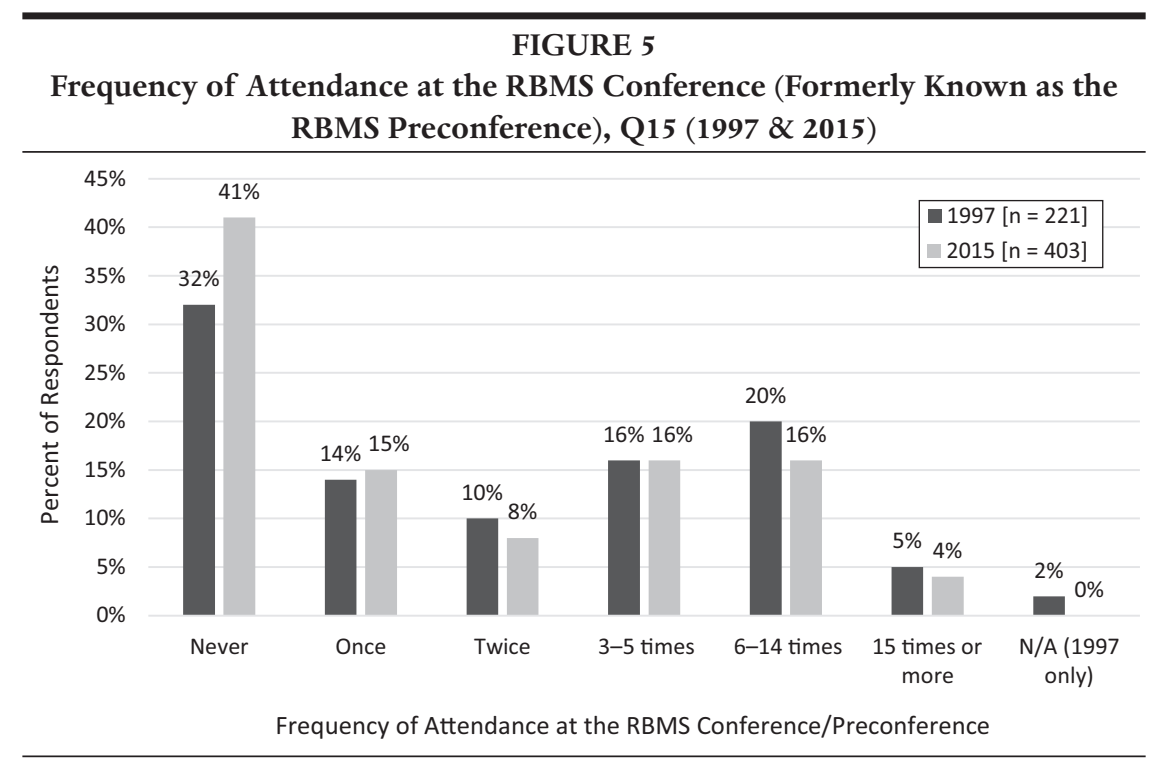

While the percentage of members who have attended RBMS within the past three years has remained constant — 45 percent in both 1997 and $2015^{55}$ - the primary reason cited for not attending has changed from one of affiliation and interest to one of financial resources. In 1997, the most common reason for not attending was being more active in other organizations (22\%); in 2015, it was the costs associated with travel and lodging $(29 \%) .^{56}$

Whereas attendance by RBMS members at the ALA Midwinter and Annual conferences has dropped, ACRL attendance has nearly doubled, as seen in figure 6. Conditional filtering of the data reveals that a little more than a quarter of respondents (28\%) have attended both RBMS and ALA Annual within the past three years; however, a new question would be needed to determine whether or not they attended both conferences in the same year. ${ }^{57}$

\footnotetext{
54. Q15 (1997 \& 2015).

55. Q16 (1997), Q16a (2015).

56. Q16a (1997), Q16b (2015).

57. Q16a, Q22a.
} 


\section{FIGURE 6}

Percent of Respondents Who Have Attended RBMS, ACRL, ALA Midwinter, and ALA Annual Conferences within the Stated Period, Q16/16a, Q18/Q18a, Q20/Q20a, Q22/Q22b (1997 \& 2015)

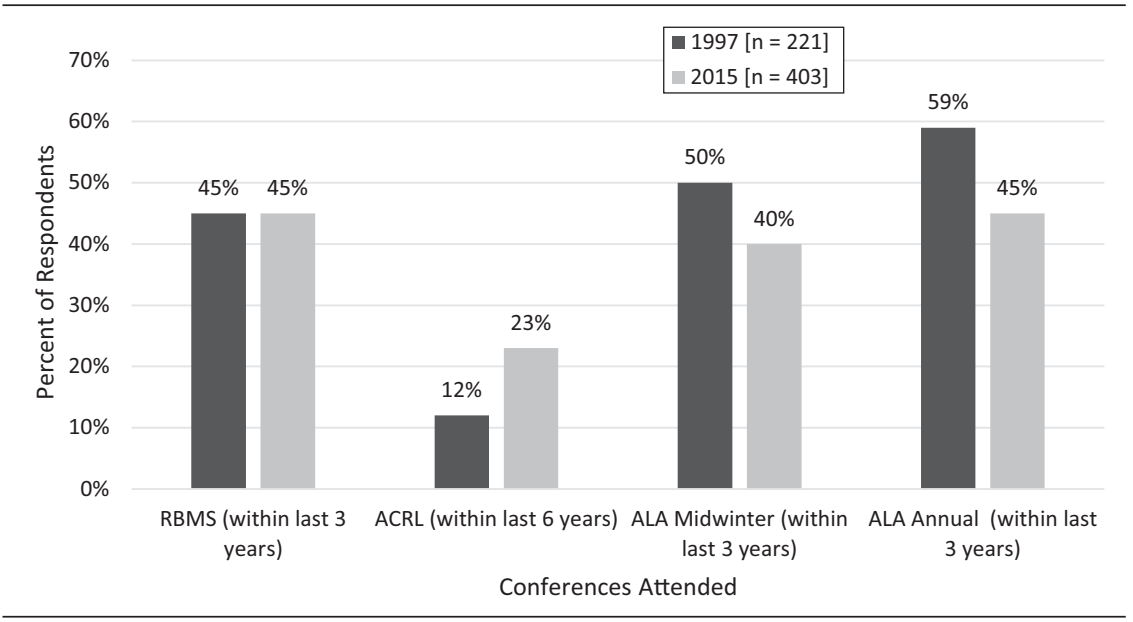

While it is customary for RBMS to meet immediately prior to ALA Annual (it has done so for 19 of the last 20 years), the RBMS Conference Development Committee has been interested to learn more about members' preferences regarding maintaining the geographic and temporal association of RBMS and ALA Annual. Accordingly, two new questions (Q22c and Q22d) were added in 2015. These questions found that while fewer than half of all respondents expressed a preference for keeping RBMS and ALA Annual geographically and temporally proximate, this percentage rose dramatically among those who had attended both conferences within the past three years. These numbers provide statistical data for the common sense supposition that those who attend both conferences are more likely to favor their proximity than those who do not.

The most commonly reported factors influencing whether members attend RBMS and ALA in the same year are expense (cited by approximately 212 members) and time (cited by 104 members). ${ }^{58}$

58. Q22d. Several members noted that they prefer RBMS and only attend ALA when they are serving on committees; a smaller number of members cited yearly responsibilities at ALA and noted that they could only attend RBMS when the conference theme was particularly relevant. See, for example, the following member responses to which factors influence whether or not they attend RBMS and ALA annual in the same year: Response 251: "Committee membership commitments (will not go if there are none). ALA offers insufficient professional development opportunities compared to RBMS for the cost in \$\$ and time." Response 172: "Topics at RBMS, Cost. I have to go to ALA, but can only go to RBMS if it is very applicable that year and the cost is low-this combo is almost never the case." 
FIGURE 7

Preferences Regarding Geographic and Temporal Proximity of RBMS and ALA Annual Conferences, Q22c, Q16a, Q22a

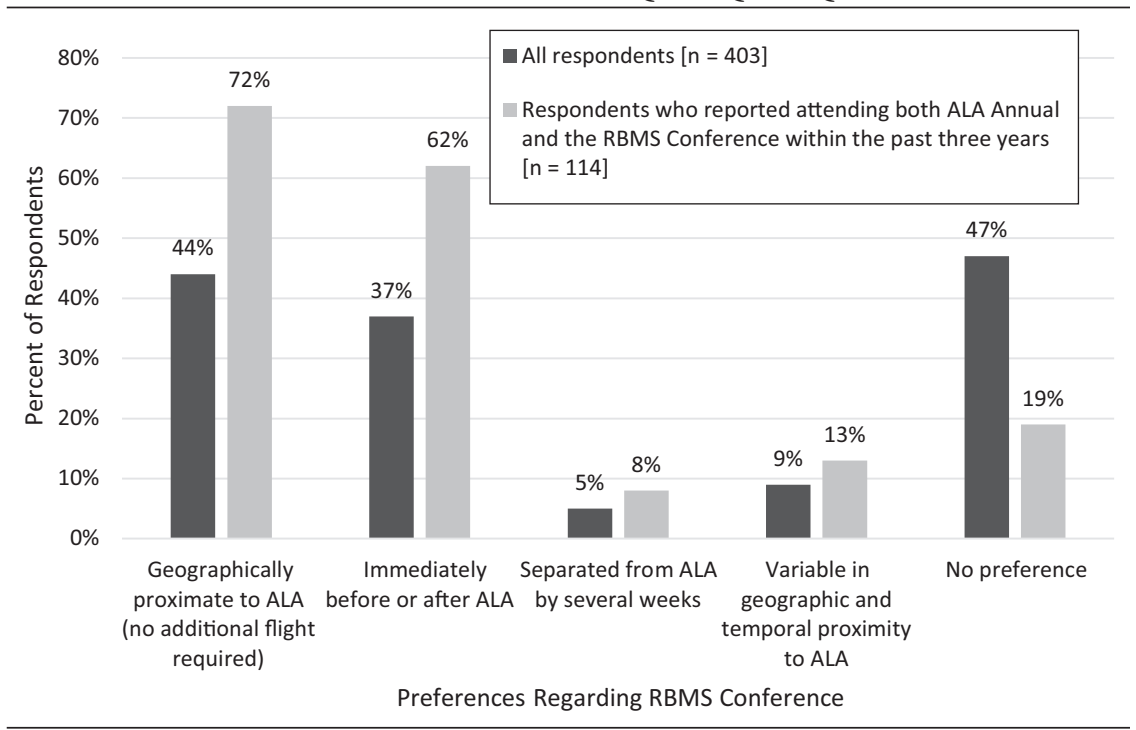

Thirty-five percent of respondents have held at least one committee or task force appointment, and 23 percent have held three or more appointments. ${ }^{59}$ Scholarship winners are nearly twice as likely to have held a committee appointment as the general survey population (60\% versus $35 \%)$. ${ }^{60}$ With respect to RBMS leadership, 6 percent of respondents have served as a member of the Executive Committee and 9 percent have served as a Committee or Task Force Chair. ${ }^{61}$

Active involvement correlates positively with member satisfaction. Whereas 61 percent of survey respondents either agree or strongly agree that their involvement in RBMS has been rewarding, this number climbs to 86 percent for those who have attended an RBMS conference within the past three years and 89 percent for those who have been appointed to at least one committee or task force. ${ }^{62}$ In cultivating more active involvement, the challenge appears to be facilitation rather than inclination, as the majority of respondents $(62 \%)$ would like to be more active in RBMS than they presently are. ${ }^{63}$ Institutional support (155 responses) and easier access to committee membership (111 responses) are the top two factors that would encourage more active participation. ${ }^{64}$

\footnotetext{
59. Q23.

60. Q23, Q32.

61. Q24, Q25. Percentages were tabulated by using the number of respondents who reported serving divided by the total survey population of 403 .

62. Q26, Q16a, Q23. Calculations are based on a response population for Q26 of 362.

63. Q28a.

64. Q28b. These were the most frequently selected options from a preset list of factors that might help encourage respondents' more active participation.
} 
FIGURE 8

Factors That Would Encourage More Active Participation in RBMS, Q28b

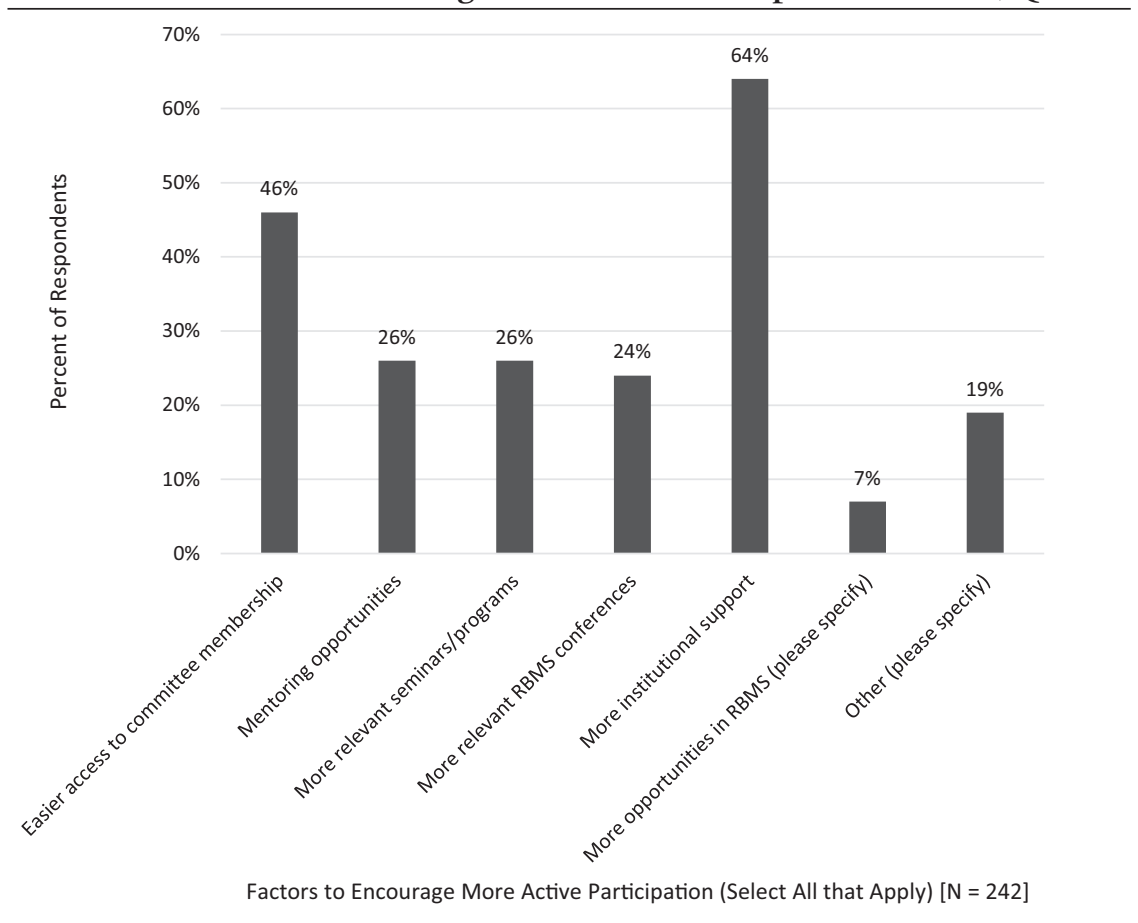

\section{The Future of RBMS and the Profession}

A series of three free-text questions (Q33-Q35) invited members to reflect on the future of the profession and RBMS as an organization. Because this section offers perhaps some of the richest insight into the priorities and concerns of members, readers are encouraged to review the full set of responses available in the 2015 RBMS Membership Survey Data Report on the RBMS website. ${ }^{65}$ Presented below is a brief summary based on the authors' coding of responses ${ }^{66}$ With respect to the "most critical issue(s) in the future of special collections librarianship," the most common areas of concern were:

- The digital environment (including digitization, born-digital materials, continued relevance of physical collections in the digital age)

- Staffing and the future of the profession (skills and knowledge needed, education and training, availability of positions, paths to leadership)

- Funding (especially coping with limited funding and increased costs)

65. “2015 RBMS Membership Survey: Data Report,” 58-85.

66. Free-text responses Q33-Q35 were coded independently by this article's two authors to determine principal comment classifications, then recoded to assess prevalence once the primary classifications had been determined. 
- Demonstrating value and relevance (to administrators, scholars, and the public)

- $\quad$ Outreach (especially to new audiences) ${ }^{67}$

In many ways, these concerns echo those described 18 years ago, which the 1997 survey report summarized as "funding, technology, preservation, support from parent institutions, justifying existence/relevance, outreach, continuing education/training." ${ }^{168}$ Despite changes in the technological and administrative contexts of our libraries, many of the sentiments underlying members' concerns remain surprisingly similar. Issues in 2015, such as "acknowledging the digital demand and getting collections online while still enticing audiences to come see the real deal" have their near-equivalents in 1997 concerns such as "[r]emaining relevant to scholarship increasingly conducted online; funding for creating digital surrogates for selected primary source materials." ${ }^{69}$

Issues cited as most critical for the future of RBMS in the 2015 survey include:

- New members (attracting and cultivating the next generation of special collections professionals)

- Diversity (of collections, members, member positions, and institution types)

- Affordability of involvement in RBMS (costs related to conferences and membership $)^{70}$

Despite the prevalence of concerns regarding recruiting new members, the survey's own internal evidence suggests that the organization is succeeding in this arena. In 2015, 24 percent of respondents were 34 or younger, in contrast to just 10 percent in $1997 .{ }^{11}$ Diversity emerged as a much more prominent concern than it had been in 1997, appearing across all three free-text questions. With respect to RBMS, respondents highlighted the need to improve both the racial and ethnic diversity of the membership and the types of libraries that participate in the organization. As one member framed the issue, "Diversity, both of members and acknowled[g] ing diversity of types of institutions within the section. We don't all work at an Ivy League or R1 institution with budgets to match." ${ }^{\text {"72 }}$ The affordability of participating in RBMS was another common thread, and several respondents linked expense to questions of diversity when enumerating critical issues: "Continuing work to diversify the profession. A close - and related — second is controlling costs and/or providing opportunities for those who can't attend the conferences." ${ }^{\text {73 }}$

\footnotetext{
67. Q33.

68. Oftelie, “1997 Membership Survey,” 33.

69. Response 105, Q33 (2015) and response 83, Q33 (1997).

70. Q34.

71. Q2 (1997 \& 2015).

72. Response 33, Q34.

73. Response 209, Q34.
} 
In 1997, "continuing education" and "regional workshops" ranked as the most desired new or expanded initiatives for RBMS to pursue. ${ }^{74}$ In 2015, respondents most frequently advocated for:

- Programming and continuing education (more of it, more easily accessible, subject recommendations)

- Remote participation (including webinars, live conference streaming, virtual committee work)

- Increased outreach to and collaboration with other organizations (including ACRL, SAA, AHA, and others $)^{75}$

The interest in greater opportunities for remote participation perhaps mirrors the earlier wish for more regional offerings, and it dovetails with the concerns regarding expense. The responses indicate a clear desire to make RBMS programming and participation more accessible, especially for those with limited institutional support and a limited capacity to travel. ${ }^{76}$

\section{Our Careers}

\section{EDUCATION}

A master's degree in library or information science is widely accepted as the main point of entry into a professional career in special collections, and, indeed, 89 percent of 2015 survey respondents hold one. Although less widely held, a master's degree in another subject is a commonly preferred qualification in many special collections job postings, and nearly half (49\%) of 2015 respondents possess one. These percentages have changed little from $1997 .{ }^{77}$

For those in the special collections field deciding whether to pursue additional education, it may be helpful to know that RBMS members in certain positions are more likely to have a subject master's or a doctoral degree. Department heads of special collections were most likely to have a subject master's, at a rate of 67 percent. Curators $(62 \%)$, rare book catalogers $(58 \%)$, and library directors $(57 \%)$ were close behind..$^{78}$

74. Q35 (1997). In 1997, respondents were prompted to rank the most important new or expanded initiatives for RBMS from a set list of options: mentoring program, regional programs, continuing education, new standards or publications, and other.

75. Q35. In 2015, the survey administrators elected to approach the topic of new and/or expanded initiatives through a free-text question to encourage members to articulate their own proposals without being limited to a set list of options.

76. See, for example, responses 14, 31-32, 44, 51, 58-59, 61, 91, 96, 101, 106, 111-112, 119, 147, 150, 153, 157, 184, Q35.

77. Q4 (1997 \& 2015). In both 1997 and 2015, a “subject master's" refers to a master's degree in a subject other than library and information science or archives. For the purposes of the survey, it may be either in addition to or in place of a library degree.

78. Q4, Q38a. 
A doctoral degree is much less common within the RBMS membership. Only 11 percent of respondents hold a $\mathrm{PhD}$, including 1 percent in library or information science and 10 percent in another subject. Overall, the number of special collections professionals with this degree is declining; 19 percent of respondents held a doctoral degree in $1997 .{ }^{79}$ Although only 11 percent of all respondents hold a doctoral degree, 40 percent of associate or assistant directors, 35 percent of library directors, and 35 percent of curators of "mixed or other formats" report having this degree. ${ }^{80}$ Another category of respondents was more likely to have doctoral degrees; while men make up just 23 percent of survey respondents, they account for half of doctoral degrees. ${ }^{81}$

The educational background of most RBMS members is grounded firmly in the humanities. Members report History and English as the top two disciplines, respectively, for their major areas of study (BA, MA, and $\mathrm{PhD}$ ). In fact, no respondents list a master's or doctoral degree in STEM (science, technology, engineering, and mathematics) fields. ${ }^{82}$

\section{POSITIONS}

The most commonly held position is that of special collections librarian (13\%); it is also the position that has seen the greatest growth since 1997, when it ranked eighth at 6 percent. The greatest decrease was a 6 percent drop in special collections department heads, perhaps reflecting the younger demographic of the 2015 survey. Nevertheless, this position still ranked as the second most popular at 12 percent. Curators overall also experienced a significant decrease, from 11 percent in 1997 to 6 percent in 2015. Although curator positions for rare books and for manuscripts decreased ( $7 \%$ to $2 \%$ and $4 \%$ to $0 \%$, respectively), a new category for curators of "mixed or other formats" was added in 2015, and it accounted for 4 percent of respondents. ${ }^{83}$ This may indicate that curator positions are moving away from being format-specific, although declining overall. More research is needed to determine whether these position changes reflect a shift in labeling trends or if they indicate a real change in job responsibilities.

With respect to administrative positions, men are represented at a higher rate than women in relation to their overall numbers. While men account for 23 percent of all respondents, they represent 30 percent of library directors, 40 percent of

\footnotetext{
79. Q4 (1997 \& 2015).

80. Q4, Q38a.

81. Q4, Q1.

82. Q4.

83. Q38 (1997), Q38a (2015). The new category represents multiformat curatorial positions (such as books and manuscripts), but also potentially curators of other formats, including photographic, audiovisual, and born-digital materials.
} 
TABLE 2

Most Common Current Positions, Q38 (1997), Q38a (2015)

\begin{tabular}{l|l|l|l}
\hline \multicolumn{1}{c|}{$1997[\mathrm{n}=221]$} & & \multicolumn{1}{|c|}{$2015[\mathrm{n}=403]$} & \\
\hline Department Head, Special Collections & $18 \%$ & Special Collections Librarian & $13 \%$ \\
\hline Rare Book Cataloger & $11 \%$ & Department Head, Special Collections & $12 \%$ \\
\hline Library Director [n $=17]$ & $8 \%$ & Rare Book Cataloger & $11 \%$ \\
\hline Associate/Assistant Director [n $=17]$ & $8 \%$ & Other [ $\mathrm{n}=34]$ & $8 \%$ \\
\hline Curator of Rare Books & $7 \%$ & Archivist $[\mathrm{n}=31]$ & $8 \%$ \\
\hline
\end{tabular}

associate or assistant directors, and 38 percent of department heads in special collections. ${ }^{84}$ Among those who have been professional librarians or archivists in the special collections field for 15 years or more, 58 percent of men and 47 percent of women are administrators. ${ }^{85}$ However, for those who have been in the field up to 14 years, the difference is much smaller: 27 percent of men and 25 percent of women in this category hold administrative positions. ${ }^{86}$ While 31 percent of all respondents are administrators, only 23 percent of respondents who identified as belonging to a racial or ethnic minority group hold one of these positions. However, a higher percentage of diverse respondents ( $9 \%$, versus $2 \%$ for all respondents) are students, which could have a positive impact on the increasing diversity of the field, provided that these students are able to obtain professional positions in the field ${ }^{87}$

FIGURE 9

Respondents in Administrative Positions (Library Directors, Associate or Assistant Directors, Department Heads, or Associate or Assistant Department Heads of Special Collections), Q38a

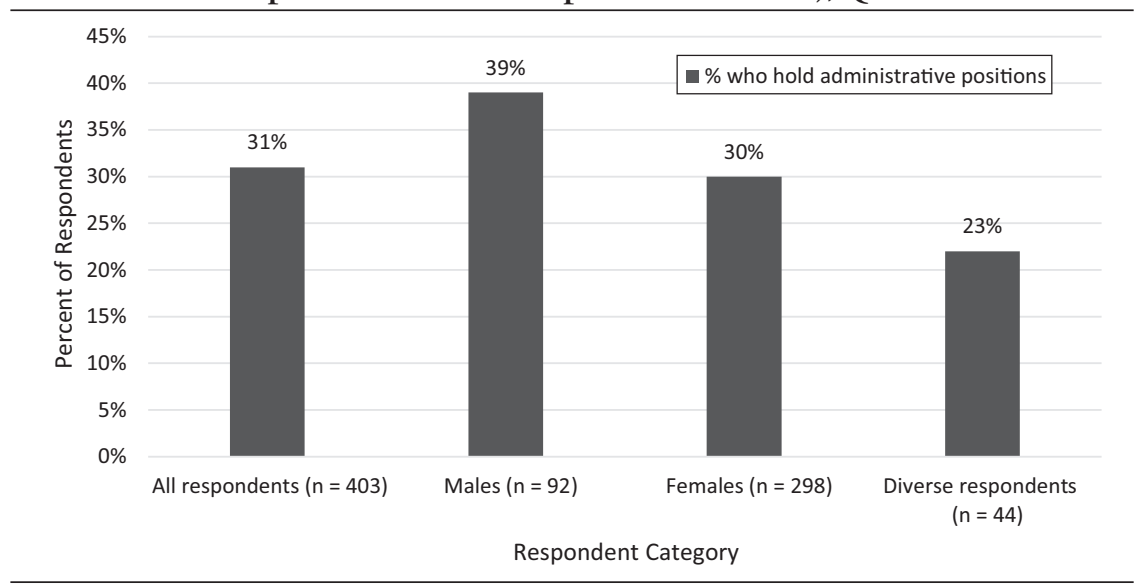

84. Q1, Q38a.

85. Q1, Q6, Q38a. Administrators include library directors, associate or assistant directors, department heads of special collections and other departments, and associate or assistant department heads of special collections.

86. Q1, Q6, Q38a.

87. Q3, Q38a. 
The survey results reveal some additional characteristics of the special collections workforce: 93 percent of respondents hold full-time positions ${ }^{88} 46$ percent have been in their current position fewer than four years (versus 37\% in 1997); ${ }^{89}$ and 47 percent have held between three and five positions in their library or archives career to date. ${ }^{90}$

\section{INSTITUTIONAL SETTINGS}

Although RBMS members represent a wide variety of institutions, from large research universities to small historical societies, most survey respondents (64\%) work in a university library. One of the more significant changes since 1997 has been in the area of independent research libraries, which employed 12 percent of 1997 respondents but only 5 percent of 2015 respondents. ${ }^{91}$ The 1997 survey report indicates that the high percentage at that time may have been the result of RBMS recruitment efforts, which have perhaps since tapered off. ${ }^{92}$
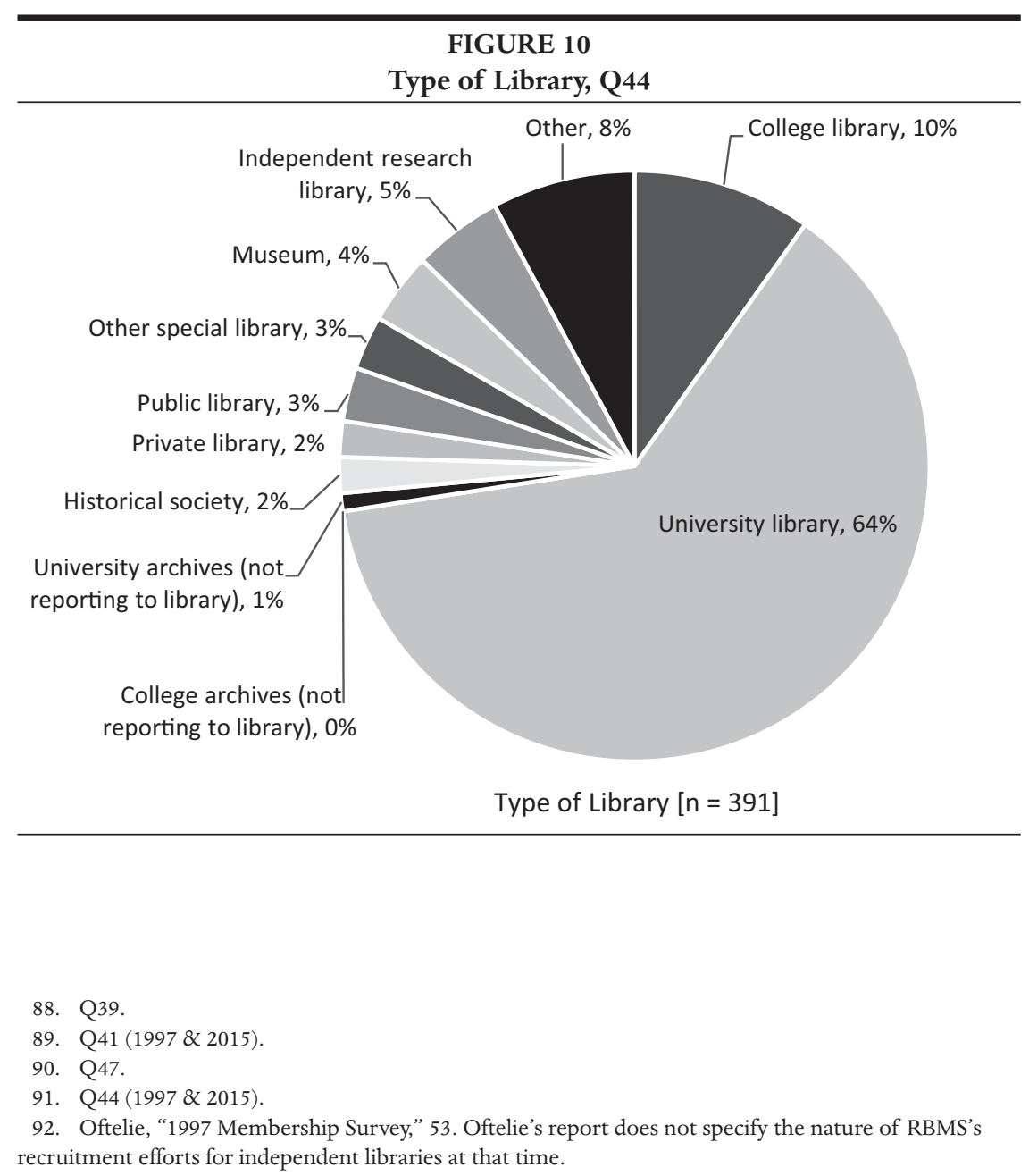
Within their institutions, nearly half of respondents report working in a "special collections" department (46\%). There is a slight trend away from those working in a "rare books" department, from 8 percent in 1997 to 5 percent in 2015, a potential indication that more departments are moving toward integrating formats. ${ }^{93}$ Fewer respondents in a "special collections, rare books, or archives" department report to collection development or public services than in 1997. Instead, more are reporting to the library director. ${ }^{94}$

Although the majority of respondents work in university libraries, there is diversity in the size of special collections departments represented. The largest category of respondents represents departments with 300,000 or more volumes (20\%). Interestingly, the second largest category represents collections of fewer than 5,000 volumes (12\%). In fact, since 1997, respondents from departments with fewer than 25,000 volumes increased significantly, from 20 percent to 32 percent. ${ }^{95}$ Some emphasis on small institutions has been evident in recent RBMS Conference programming, including discussion groups and a seminar focused on this demographic. ${ }^{96}$ Responses to free-text questions, however, indicate that members from smaller institutions are eager to see more programming that is relevant to the nature of their work and would like additional opportunities to contribute to the organization. For example, in response to the question, "What do you see as the most critical issue(s) in the future of RBMS?" one respondent wrote, "There needs to be a way to get new members more involved in running things, and to give people from smaller and lesser-known institutions opportunities to present and make their voices heard." 97

While 18 percent of respondents were unable to estimate the size of their special collections in terms of volumes, a full 60 percent were unable to estimate the size of their archives and manuscript collections. ${ }^{98}$ Among those who were able to provide estimates, collection descriptions varied greatly and included linear feet, cubic feet, number of items, number of collections, and even miles or kilometers of materials. These responses indicate a dire need for practical and standardized

\footnotetext{
93. Q42 (1997 \& 2015).

94. Q43 (1997 \& 2015). Reporting to collection development: 11 percent in 1997; 7 percent in 2015. Reporting to public services: 17 percent in 1997; 7 percent in 2015. Reporting to library director: 47 percent in 1997; 62 percent in 2015.

95. Q46 (1997), Q46a (2015). The percentages for 2015 are based on the total number of respondents to the question, including those who were unable to estimate (391). Due to skip logic employed in the survey tool, the respondents who indicated that they did not work in a library setting did not receive this question. The percentages for 1997 are based on the total number of survey respondents, including those who were designated " $\mathrm{n} / \mathrm{a}$."

96. Discussion sessions for small and medium-sized institutions were held at the 2009, 2010, and 2011 RBMS Preconferences, and a seminar entitled "Make It Work: Creative Solutions to Common Problems" was held at the 2015 RBMS Conference.

97. Response 192, Q34. See also response 132, Q33.

98. Q46a, Q46b.
} 


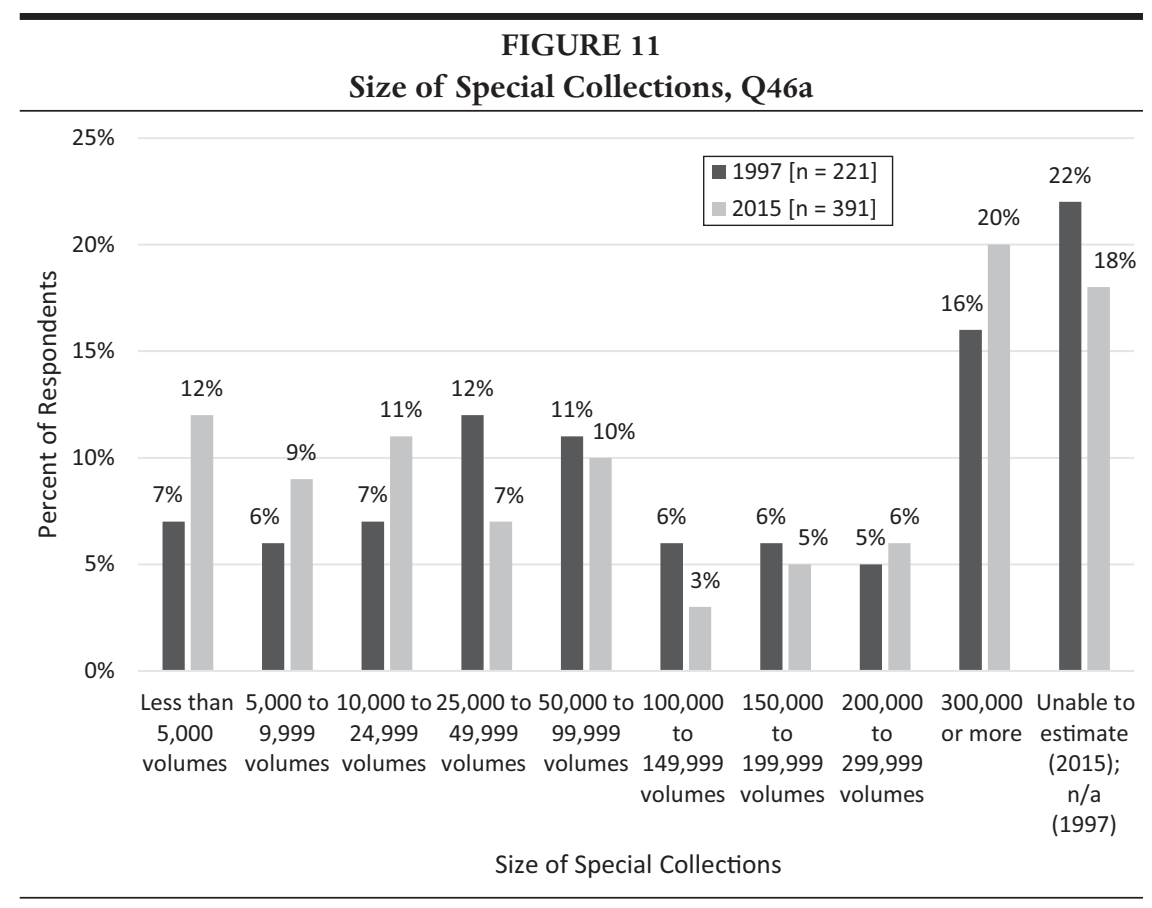

methods for counting our collections. Currently, the ACRL/RBMS-SAA Task Force on the Development of Standardized Holdings Counts and Measures for Archival Repositories and Special Collections Libraries is charged with "the development of guidelines that will provide metrics, definitions, and best practices for quantifying the holdings of archival repositories and special collections libraries."99 The results of their work will make future comparisons more meaningful.

In the 2015 survey, several new questions were added on the topic of faculty status for special collections professionals. Respondents were split nearly evenly: among respondents employed by a college or university, 52 percent report that their institution offers faculty status for librarians. However, slightly fewer respondents (46\%) are in faculty positions ( $29 \%$ tenure track and $17 \%$ non-tenure track). ${ }^{100}$

\section{SALARIES}

RBMS member salaries have increased in the 18 years since 1997, although by some measures, they are not keeping pace with inflation. The average salary in 2015 for members who provided salary information was $\$ 63,205$, a 37 percent increase over

99. "ACRL/RBMS-SAA Task Force on the Development of Standardized Holdings Counts and Measures for Archival Repositories and Special Collections Libraries," Association for College and Research Libraries, American Library Association, available online at www.ala.org/acrl/rbms/acr-rbmtfhc [accessed 27 October 2015].

100. Q38b, Q38c. 
the average 1997 salary of $\$ 46,108 .{ }^{101}$ During the same period, the U.S. inflation rate was approximately 48 percent. ${ }^{102}$ However, it is important to note that respondents to the 1997 survey tended to be more advanced in their careers, which impacts the average salary.

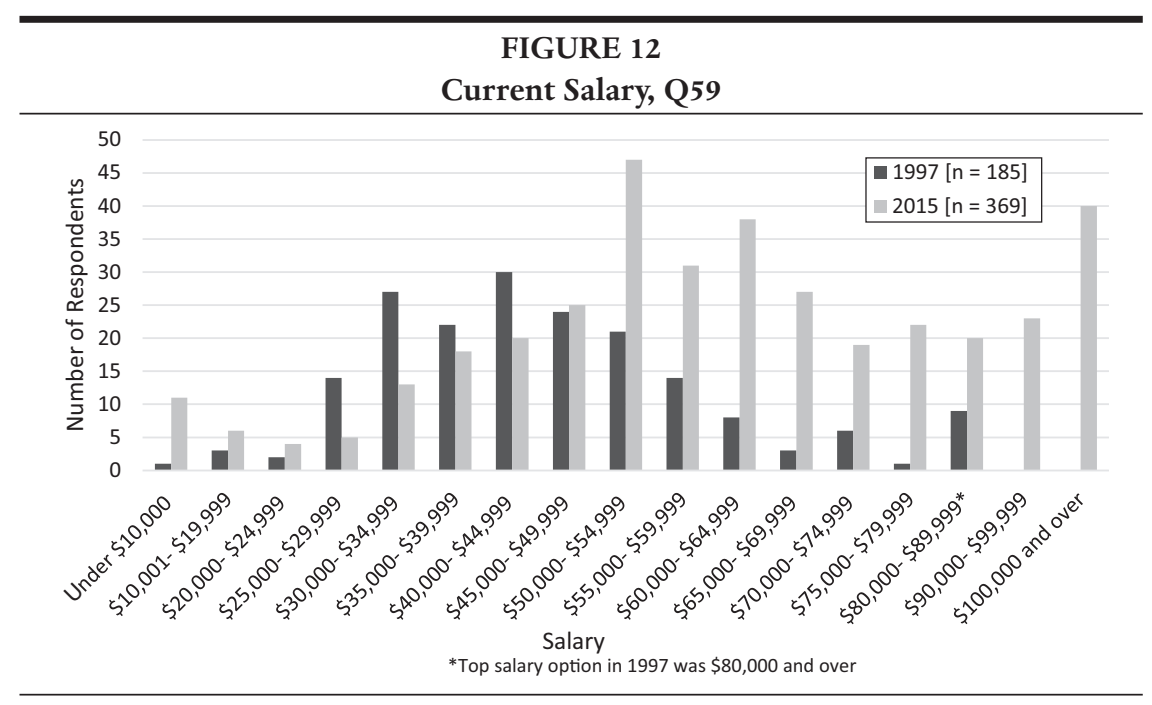

Several factors correlate with a respondent having a higher salary. In general, administrators, those with additional education, men, white respondents, and those living in certain geographic locations were all more likely to have higher salaries. ${ }^{103}$ Women and diverse respondents had lower salaries overall. While 34 percent of respondents who provided salary information report earning more than $\$ 70,000$, this number rises to 48 percent for library directors, 67 percent for associate or assistant directors, and 52 percent for special collections department heads. Nonadministrative positions tend to have higher representation in the middle salary range. For example, 70 percent of special collections librarians, the largest category of respondents, earn between $\$ 40,000$ and $\$ 69,999 .{ }^{104}$

101. Q59 (1997 \& 2015). To calculate the average salaries that are reported in this section, the authors identified a midpoint for each salary range, multiplied the number of respondents who selected that range by the midpoint, added these products together, and divided by the total number of respondents for that question (not including those who selected "prefer not to answer"). For example, the midpoint for the $\$ 50,000$ to $\$ 54,999$ range is $\$ 52,500$. For salary ranges that did not have a midpoint, the authors selected a salary that seemed appropriate. For "under $\$ 10,000$, " $\$ 5,000$ was used. For "over $\$ 80,000$ " (1997 survey), \$90,000 was used, and for " \$100,000 and over" (2015 survey), \$110,000 was used. Different salaries could be chosen for these ranges and the averages recalculated.

102. Inflation rate calculated using the CPI Inflation Calculator provided by the Bureau of Labor Statistics, available online at www.bls.gov/data/inflation_calculator.htm [accessed 1 November 2015]. 103. For example, respondents from California who provided salary information earn an average of $\$ 71,667$, which is $\$ 8,462$ more than the average salary overall.

104. Q38a, Q59. Percentages based on the number of respondents who provided salary information. It is important to note that these percentages are based on a small subset of respondents. 
Respondents with a master's degree in a subject other than library and information science earn an average salary of $\$ 68,165$, which is $\$ 4,960$ more than the average for all respondents. Those with doctoral degrees, either in library or information science or in another subject area, fare even better. Of the 38 doctoral degree holders who provided salary information, 24 earn more than $\$ 70,000 .{ }^{105}$

Despite being a predominantly female profession, men tend to earn higher salaries than women. Male special collections librarians and curators report earning an average of $\$ 69,342$, while women in these positions earn $\$ 59,230$. Similarly, male special collections department heads earn an average of $\$ 81,324$, while women earn $\$ 73,333 .{ }^{106}$ Relative length of time in the field appears to play a role in this disparity. Women in these positions tend to be earlier in their careers than their male counterparts, as they are overall in the survey population, which may help explain their lower salaries. ${ }^{107}$ Among special collections professionals who have been in the field 14 years or fewer, men earn only marginally more than women, but the gap widens for those with 15 or more years in the field. Men in that category earn an average of $\$ 88,041$, while women earn an average of $\$ 76,444 .{ }^{108}$ The extent of the gender-based salary gap is difficult to ascertain due to the complexity of variables at work, but the pattern is strong enough to warrant further investigation.

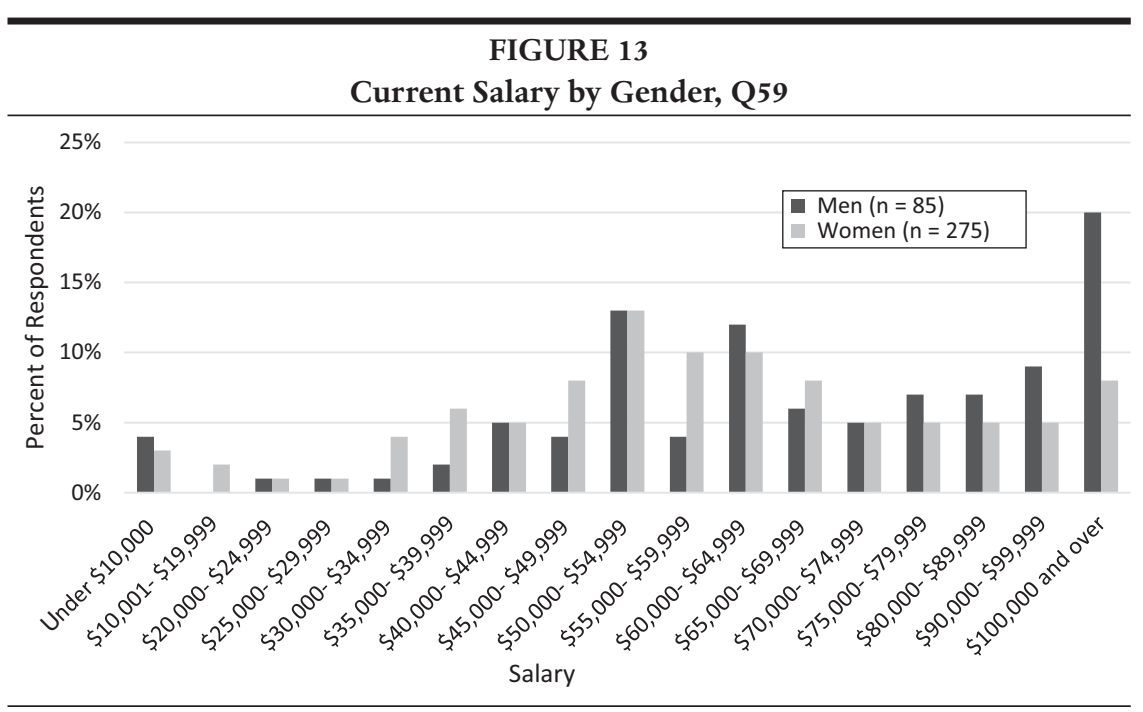

105. Q4, Q59.

106. Q1, Q38a, Q59. The salary gap noted in the RBMS survey is more pronounced than that recorded in the ARL Annual Salary Survey 2014-2015, which found that women in the position of "Dept. Head, Rare Books/Manuscripts/Special Collections" at ARL university libraries earn only slightly less than men in the same position (\$94,854 versus \$96,732). ARL Annual Salary Survey 2014-2015, comps. and eds. Martha Kyrillidou and Shaneka Morris (Washington, D.C.: Association of Research Libraries, 2015), Table 18. 107. Q1, Q6, Q38a. For example, 39 percent of male special collections department heads have been in the field for 20 years or more, whereas only 28 percent of women have.

108. Q1, Q6, Q59. Men with up to four years of experience earn an average of $\$ 53,000$, while women earn $\$ 51,111$. With 5 to 14 years of experience, men earn $\$ 66,635$ and women earn $\$ 65,118$. 
Respondents from racial and ethnic minorities earn an average of $\$ 8,510$ less than all respondents $(\$ 54,695$ versus $\$ 63,205) .{ }^{109}$ The particularly low number of respondents from underrepresented groups makes salary comparison based on position type and years in the field difficult. This gap should be monitored as future surveys provide additional data.

\section{Conclusion}

The variety of topics covered by the 2015 RBMS Membership Survey prevents its results from being distilled into any single overarching narrative. Rather, the survey's value lies at least in part in the range of initiatives and avenues of inquiry that its data might help inform. We encourage readers to consult the 2015 RBMS Membership Survey Data Report (http:/ / rbms.info/files/committees/membership_and_professional/2015_RBMSDataReport.pdf) to explore in greater detail those areas that are of particular interest to them. At the same time, the authors have observed several trends that we believe merit further consideration, and we highlight three of these in closing.

\section{Shifting Demographics}

Comparing the results of the 1997 and 2015 RBMS membership surveys offers some evidence for shifting demographics within the organization and, potentially, the profession. The 2015 findings point to an influx of younger professionals, with better age distribution more broadly and small increases in diversity (though there is still much room for improvement there). However, the findings also suggest that there are some populations on the decline: $45-54$ year-olds (an age demographic that had previously been dominant within the organization, and one whose waning will soon impact the next bracket up as the cohort ages), men (whose numbers have fallen by more than $10 \%$ ), and $\mathrm{PhD}$ holders (who saw an $8 \%$ decline). The survey also records shifts in member positions, with a decrease in format-based and curatorial positions and an increase in special collections librarians. A growing portion of the membership is interested in archival materials, as increases in readership of the SAA listserv, SAA membership, and the rise in position prevalence of archivists attest. ${ }^{110}$

Such changes provoke as many questions as they answer. At the most basic level, there is the question of whether the response rates of the two surveys (12\% in 1997 and $28 \%$ in 2015) provide a firm enough basis for any longitudinal claims. The best way to determine the validity of the trends noted above and to identify

109. Q3, Q59. Respondents from racial and ethnic minorities include those who self-identify as American Indian or Alaska Native, Asian, Black or African American, Hispanic or Latino, Native Hawaiian or other Pacific Islander, two or more races, or other. 110. Q10 (1997 \& 2015), Q12 (1997\& 2015), Q38 (1997), Q38a (2015). 
further changes in the field is by continuing to gather data. Higher response rates and more frequent data collection will enable us to track trends with greater confidence.

Other observations call out for more study to provide a fuller picture. If the seeming decline in $\mathrm{PhDs}$ is not the product of sampling errors, what is its cause? What does it suggest about the shifting requirements for the twenty-first century special collections professional and the relative value of subject expertise, as compared with other types of knowledge, such as technological skills or a broad, generalist background? With respect to positions, do the changes observed indicate a genuine shift in the core functions of professionals in the field, or are they more reflective of labeling trends? Why didn't we see the explosion in "new" position types (such as outreach/instruction librarians or digital archivists) that we might have expected, given the growth in digital collections and the increased emphasis on instruction and outreach since the last survey? These remain open questions, and one of the most important things that this survey can do is identify areas that require further study and inspire us to undertake this research.

\section{Diversity and Gender Imbalances}

While racial and ethnic diversity within the section has increased in the 18 years since the 1997 survey, the organization remains less diverse in 2015 than the country as a whole. The initiatives implemented in the intervening years seem to be making a difference, and the section should continue to support these initiatives while also considering additional actions to continue to increase diversity. Perhaps more alarming than the slow growth in diversity is the finding that diverse respondents have lower representation in administrative positions and lower salaries overall. This could be tied to number of years in the profession, since diverse respondents tend to skew younger, but it will be important to ensure that this disparity decreases as the cohorts age.

Imbalances also emerged in regard to gender. The percentage of men in the field has dropped significantly in the past 18 years (from $36 \%$ to $23 \%$ ). If we agree that a diverse professional workforce is the ideal, how might RBMS encourage men to enter the field? On the other hand, while women occupy a dominant (and growing) percentage of the profession, they are underrepresented in administrative roles and have lower salaries than men. A more systematic examination is needed to uncover why the gender imbalances increase among later career professionals. Is this pattern due to a legacy from past years when a gender-based salary gap was more common across all professions? If so, perhaps the smaller gaps among younger professionals indicate that these inequities are improving. Or does the pattern indicate that, as women approach the later stages of their careers, they are less 
likely than men to transition into leadership roles and higher-paying positions? One way to determine this will be to monitor whether these younger cohorts maintain the near-equity they currently have as they age. It will also be important to note whether future generations of special collections professionals close the gap altogether. In the meantime, although recruiting women into the profession is clearly not an issue, the organization might consider developing initiatives to ensure that women have opportunities to advance professionally and financially throughout their careers.

\section{Expense as a Barrier to Participation}

The survey also shines a light on the degree to which expense is increasingly becoming a barrier to participation in RBMS. Though concerns over costs were present in 1997 and were even raised by some as among the most critical issues for the future of RBMS in that survey, ${ }^{111}$ the 2015 survey witnessed a proliferation of such concerns, as noted in the discussion section above. Whereas 1997 respondents ranked expense as the sixth out of ten areas in which RBMS might improve, 2015 respondents ranked it as their highest out of eleven options. ${ }^{112}$ Part of the challenge lies in what might be called the three-conference dilemma: while most professional development and discipline-based programming for RBMS takes place at the RBMS Conference, members who wish to serve on committees must generally attend ALA Annual and Midwinter for committee work. As one member explained it, "[...] The financial burden of attending, in effect, three conferences (even if no second plane ticket is needed for ALA, the extra hotel/food/registration is significant) is crushing." 113 And yet members do want to participate; the majority of members $(62 \%)$ report a wish to be more active in RBMS than they currently are (as compared with $42 \%$ in 1997), and they cite "more institutional support" as the top factor that would encourage their more active participation. ${ }^{114}$ The result is a gap between enthusiasm for involvement and the resources necessary to facilitate that participation.

Moreover, how is RBMS to respond to the call to diversify its membership (another common thread throughout the survey) and reach out to members from smaller institutions or in paraprofessional positions when these are often the members least likely to receive financial support and paid leave from their institutions for confer-

\footnotetext{
111. Q34 (1997). For examples of concern about the cost of membership and conference attendance in the 1997 RBMS Membership Survey, see responses 24, 41, 53, 54, 60, 73, 99, 100, 108, and 113. Oftelie, "1997 Membership Survey," 40-45.

112. Q21. In both 1997 and 2015, the survey asked respondents to rank the top three areas in which RBMS needs improvement. To generate a comparative ranking among the responses in both surveys, the responses in each survey were weighted according to the following system of assigning points: 1 $($ top choice $)=3$ points; 2 (second choice $)=2$ points; 3 (third choice $)=1$ point.

113. Response 201, Q22d.

114. Q28a (1997 \& 2015).
} 
ence attendance? The increased concern over costs suggests areas for further study: have the costs associated with participating in the RBMS and ALA conferences increased at a rate faster than inflation, and/or are the institutional funds available to librarians and archivists for professional development declining?

If expense is becoming an increasingly exclusionary force, RBMS should revisit with greater intentionality two initiatives for which members indicated interest in the survey:

- Expanded virtual committee participation, including exploring the impact this would have on the work of committees and which committees are better suited to virtual participation

- Webinars and live conference streaming, including an exploration of the technological infrastructure needed and an analysis of the financial impact these might have on the profitability of the RBMS Conference

Although such proposals are not without their own difficulties, as several respondents have recognized, the push for an increase in low-cost opportunities for involvement suggests that a programmatic approach to exploring virtual participation (perhaps under the auspices of a Task Force) may be warranted.

Despite the concerns and issues raised by the survey findings, the overall picture of RBMS members is that they are engaged, perceptive, and passionate about their profession. As members work to improve their institutions and the field at large, gathering survey data on a more regular basis will enrich our understanding of the profession and contribute to evidence-based decision making. Special collections and archives will and must continue to transform in response to and in conversation with changes in technology, higher education, and researcher needs. Fostering an accessible and vibrant professional community will empower us to address, collectively, the challenges and opportunities ahead.

\section{Opening Doors to Collaboration, Outreach and Diversity}

\section{Register today! www.conference16.rbms.info}

\begin{tabular}{l|l|l|l}
$\mathbf{R}$ & $\mathbf{B}$ & $\mathrm{M}$
\end{tabular}

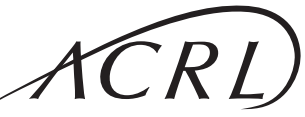

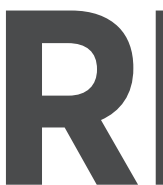
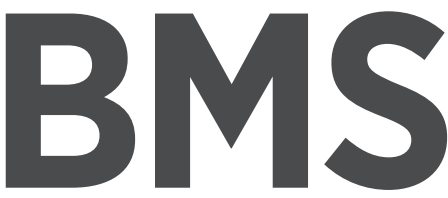

JUNE 21-24 CORAL GABLES, FL 